\title{
WOOD ONE-SIDE SURFACE CHARRING OF TIMBER FOR CLADDINGS OR RECYCLED WOOD
}

\author{
Andris Morozovs ${ }^{1}$, Laura Laiveniece ${ }^{2}$, Valters Lubinskis ${ }^{3}$ \\ ${ }^{1}$ Latvia University of Life Sciences and Technologies, Latvia; \\ ${ }^{2}$ Forest and Wood Products Research and Development Institute, Latvia; \\ ${ }^{3}$ Pavasars wood constructions Ltd, Latvia \\ andris.morozovs@1lu.lv, laura.laiveniece@e-koks.lv, valterslubinskis@gmail.com
}

\begin{abstract}
Wood is renewable and carbon dioxide neutral resource for construction, but world population grown, urbanization, and climate changes diminish this resource. The sustainable technologies must be used to extend timber service life as well as save forest resources by reuse of timber. The objectives of the presented research were 1) to develop one-side wood surface charring method and evaluate char layer hydrophobity; 2) estimate influence of inorganic mater presence in wood surface on its charring process by surface modification with sodium silicate as model for demolition wood; 3) estimate organic acids effect on charred wood surface colour and hydrophobic performance; 4) work out a method for assessment of water vapour uptake through one-side wood surface. Scots pine (Pinus sylvestris L.) samples without initial treatment or modified with sodium silicate solution as model of recyclable wood or surface impregnated with formic acid were charred in the laboratory electrical oven at different temperatures from $300{ }^{\circ} \mathrm{C}$ up to $800{ }^{\circ} \mathrm{C}$. Charred wood surface colour were evaluated according to CIE $L * a * b *$ method and surface hydrophobity by developed one-side water vapour absorption. It was found that wood samples mass loss (ML) well correlated with thermal treatment intensity. Wood char layer does not shelter underlying wood against humidity. Based on results of water vapour up-take through charred before modified with sodium silicate wood surface was found that inorganic compounds increased surface hydrophilicity. Surface pretreatment with formic acid increased one side charred wood hidrophobity. Wood char colour redness $a^{*}$ and yellowness $b^{*}$ low values confirm high wood's charring degree. The method of water vapour absorption through charred wood surface were developed.
\end{abstract}

Keywords: char colour, charring, formic acid, water vapour uptake, wood surface.

\section{Introduction}

Growing interest in green construction increases the need for sustainable renewable materials Wood is renewable and carbon dioxide neutral resource for construction. Thanks to its natural origin, its extensive availability, its relatively simple and ease mechanical workability, its high specific strength, wood is widely used today as a construction material. However, if we increasing our reliance on wood we must live according to the possibilities, therefore, we must ensure that we make the best use of our limited resources and ensure that the forests remain healthy [1].

There are an increased need for higher performance in outdoors high durability wood products with limited need for maintenance, homogeneous and pleasurable appearance. Many of these key requirements are extremely challenging for standard wood products to meet them. Other challenges such as increasing constraints on use of efficient chemicals for protection and durability improvement decreases the competiveness of wood products [2].

When the moisture content within the wood is sufficiently high, it is susceptible to biological attack and becomes corrosive towards embedded metal fasteners. Furthermore, periodical large changes in wood moisture content cause dimensional instability, which can lead to the formation of splits and checks within the wood and failures at wood-adhesive bond-lines [3]. Wood thermal modification (TM) will reduce cell wall moisture content that will prevent fungal decay growth. TM has been employed as an industrial method to improve the performance of solid wood products without usage of chemicals approximately two decades [4]. Five main commercial methods for the wood TM have been developed in Finland, Germany, the Netherlands, and France [5].

Regardless of the process used, TM wood exhibits lower mechanical strength that prevents its use in load-bearing structures [5-7]. The brown TM wood colour is not stable and it change to grey in outdoors exposure and cracking takes place. In entirely the maintenance intervals cannot be significantly decreased compared to unmodified wood [8-10]. Čermák et al. showed that TM wood dimensional stability decreases when subjected to cyclic wetting-drying [11]. As an option to increase the TM wood mechanical strength it could be modified only from the exposed surface as has been utilized traditionally 
in Japan by the wood charring with naked flame and the result is practically maintenance-free and service duration last up to hundred years [1].

Wood heating in presence of oxygen is similar to a fire conditions. Wood typically undergoes three main stages of pyrolysis due to its relatively low thermal conductivity and density and relatively high specific heat: dehydration and very slow pyrolysis below $200{ }^{\circ} \mathrm{C}$, onset of pyrolysis up to $300{ }^{\circ} \mathrm{C}$, and rapid pyrolysis above $300^{\circ} \mathrm{C}$. Mass loss due to pyrolysis occurs slowly at temperatures below $200^{\circ} \mathrm{C}$ [12-14]. Prolonged heating at low temperatures can convert hemicellulose (and lignin) into a carbonaceous char leaving cellulose largely unreacted [13]. Hemicellulose is the first wood polymer component that decomposes at heating from $200{ }^{\circ} \mathrm{C}$ to $300{ }^{\circ} \mathrm{C}$ [15]. Cellulose is the next compound to decompose, with decomposition temperatures interval from $250{ }^{\circ} \mathrm{C}$ to $400{ }^{\circ} \mathrm{C}$ [16-20]. High heating rates favour the production of flammable vapours and little or no char [18; 21]. Lignin usually undergoes pyrolysis at temperatures interval from $225^{\circ} \mathrm{C}$ to $450{ }^{\circ} \mathrm{C}$. Lignin produces aromatic nature pyrolysis products. Approximately half of lignin remains as char [16]. At temperatures between $300^{\circ} \mathrm{C}$ and $500{ }^{\circ} \mathrm{C}$, wood pyrolysis rates increase rapidly [19] due to temperatures increase by additional exothermic reactions. Char layer and its cracking leads to not uniform heating of under-laying wood. Cracks in char layer additionally facilitate the emission of volatiles from pyrolysis zone [16]. The temperature ranges of wood components pyrolysis are dependent on the heating rate, species, density, or moisture content [16]. Dry wood usually ignite in about half the time needed for wood with $12 \%$ moisture content [18]. Wood with higher density will char more slowly by the endothermic pyrolysis character. Low-density wood chars faster due to poorer heat transfer [22]. The presence of moisture is retarding pyrolysis [17; $19 ; 22]$ due to the greater energy requirements to evaporate the water. Another significant factor affecting pyrolysis rate is the species of the wood $[12 ; 18 ; 22-25]$. In general the charring rate of wood is affected by chemical composition and anatomy, density, moisture content, and permeability being dependent from wood's species and tree growing conditions [12].

The outer factors that affect wood charring are the heat and mass transfer [12]. Wood permeability and thermal conductivity is greater parallel to the grain that determine greater charring rate parallel to the grain [12]. The presence of a char layer acts as protector for the underlying wood $[12 ; 14 ; 22 ; 23]$. It is accepted that charring rate increases with increasing heat flux $[16 ; 26 ; 27]$ and decreases with decreasing oxygen concentration [24].

Wood one-sided surface charring with hot plate was suggested as suitable technique for one-sided exposed wood surfaces (wood cladding, wooden shingles) [1] or all side charred wood for use in wet environments [28]. The objectives of the presented research were 1) to develop one-side wood surface charring method and evaluate char layer hydrophobity;2) estimate influence of inorganic mater presence in wood surface on its charring process by surface modification with sodium silicate as model for demolition wood; 3) estimate organic acids effect on charred wood surface colour and hydrophobic performance; 4) work out a method for assessment of water vapour uptake through one-side wood surface.

\section{Materials and methods}

Wood samples. Pine wood samples (Pinus Silvestris) $100 \times 100 \times 20 \mathrm{~mm}^{3}$ (grain, tangential and radial) were cut from tangential boards without visible faults and sanded from all sides. Only samples of clear wood were selected, avoiding defects, such as knots, rot, juvenile and reaction wood etc. Samples after conditioning in the laboratory for a month were weighted $\pm 0.01 \mathrm{~g}$ and measured in the grain, tangential and radial direction $\pm 0.01 \mathrm{~mm}$. In parallel ten reference samples for each treatment series were dried in an ventilated oven at $103 \pm 1{ }^{\circ} \mathrm{C}$ and weighted and measured before and after drying to obtain water content and shrinkage values for adjusting of experimental samples to oven dry parameters. Number of sample species in test series was 10 and total number of wood samples were 300 .

Wood charring. Wood samples were charred uncovered or covered with aluminium foil except one tangential surface. Metallic frame with $90 \times 90 \mathrm{~mm}^{2}$ window were used to fix and protect the aluminium foil. Wood charring was carried out in the electrical oven at different temperatures $300{ }^{\circ} \mathrm{C} ; 400{ }^{\circ} \mathrm{C}$; $450{ }^{\circ} \mathrm{C}, 500^{\circ} \mathrm{C}$ and $800^{\circ} \mathrm{C}$. Wood samples in the oven were placed on porcelain supports. Sample placement time in the oven was fixed as the charring start and take-off time as the end. Samples after 
charring were dried in ventilated oven at $103 \pm 1{ }^{\circ} \mathrm{C}$ till constant mass and mass loss (ML) was calculated by Eq.1.

$$
M L=\frac{m \cdot\left(1-\mu_{w}\right)-m_{c h}}{m \cdot\left(1-\mu_{w}\right)} \cdot 100
$$

where $M L-$ wood sample mass loss by charring, \%;

$m$ - mass of wood sample, $\mathrm{kg}$;

$\mu_{w}$-ratio of moisture content in the reference wood samples average;

$m_{c h}$ - mass of oven-dry charred wood sample, $\mathrm{kg}$.

Wood surface modification with sodium silicate. Commercial sodium silicate $\left(\mathrm{Na}_{2} \mathrm{SiO}_{3}\right)$ (SS) solution with solid content $45 \%$ were used diluted with distilled water to solid content $9 \%, 11 \%, 15 \%$, or $18 \%$. Wood sample surface were impregnated with solution by immersing surface into thin layer of reagent or by brushing four times with weighing between treatments. Samples were conditioned in laboratory to polymerize the impregnated SS before charring. Reagent uptake was calculated as weight gain (WG) according Eq.2.

$$
M G=\frac{m-m_{t}}{m \cdot\left(1-\mu_{w}\right)} \cdot 100
$$

where $M G$-mass gain by wood surface treatment with sodium silicate solution, \%;

$m$ - initial weight of wood sample before treatment, $\mathrm{kg}$;

$m_{t}-$ weight of wood sample after treatment, $\mathrm{kg}$.

Water vapour absorption in charred wood were evaluated by two modes 1) liquid water uptake and 2) absorption of water vapour through charred surface. Liquid water uptake were determined by immersing of all surfaces charred wood samples in water at room temperature or additionally in hot water at $90{ }^{\circ} \mathrm{C}$ in the reactor with forced circulation. Water vapour absorption through charred and reference wood surfaces were performed with samples dried till constant mass at $103{ }^{\circ} \mathrm{C}$ and then cooled to laboratory environment temperature in the desiccator under granulated calcium chloride $\left(\mathrm{CaCl}_{2}\right)$. Then samples were weighted and placed on beakers with distilled water. The distance between water layer and wood surface was $10 \mathrm{~mm}$. The samples were periodically weighted to obtain kinetic of water vapour absorption. Accumulated water ratios into charred and reference wood for both absorption modes were calculated by Eq. 3 .

$$
A W=\frac{m_{c}-m_{i} \cdot\left(1-\mu_{w}\right)}{m_{i} \cdot\left(1-\mu_{w} \mu\right)} \cdot 100
$$

where $A W$ - accumulated into wood water ratio, \%;

$m_{c}$ - mass of wood sample at current measurement, $\mathrm{kg}$;

$m_{i}-$ initial mass of wood sample, $\mathrm{kg}$.

The comparative hydrophobicity alteration efficiency by charring in comparison with reference wood was calculated by Eq. 4 .

$$
C H=\frac{A W_{r e f}-A W_{c h}}{A W_{c h}} \cdot 100
$$

where $\mathrm{CH}$ - comparative hydrophobicity, \%;

$A W_{\text {ref }}$ - accumulated wood ration of reference wood, $\%$,

$A W_{c h}-$ accumulated wood ration of charred wood, $\%$.

Wood surface colour measurements. Colour was measured with the Minolta CM-2500d spectrophotometer (Konica Minolta, Tokyo, Japan) with D65 light source, d/8 measuring geometry, and $8{ }^{\circ}$ standard observer (Konica Minolta. Tokyo, Japan). Each sample surface colour was measured in 5 spots (four of them near corners and one in the centre). The averages of $L^{*} a^{*}$ and $b^{*}$ values were calculated. These values were used to calculate colour parameter differences between treated and reference samples $\Delta L^{*}, \Delta a^{*}$, and $\Delta b^{*}$ to get the total colour change $\Delta E^{*} a b$ according to Eq. 5 [29].

$$
\Delta E^{*} a b=\sqrt{\left(\Delta L^{*}\right)^{2}+\left(\Delta a^{*}\right)^{2}+\left(\Delta b^{*}\right)^{2}}
$$

where $L^{*}$ - indicates the lightness in the range from black (0) to white (100); $a^{*}$ and $\mathrm{b} *-$ define the position in the green-red and blue-yellow axis respectively $( \pm 100)$. 
Wood sample one-side impregnation with formic acid. Wood samples tangential surface were brushed two times with $90 \%$ formic acid. The $5 \mathrm{~mm}$ wide edge bands of wood sample surface were not covered to prevent edges effects. The formic acid uptake $\left(M G_{F a c}\right)$ were obtained using Eq. 4.

$$
M G_{F a c}=\frac{m_{t}-m\left(1-\mu_{w}\right)}{m\left(1-\mu_{w}\right)} \cdot 100
$$

where $M G_{F a c}-$ formic acid uptake, \%;

$m_{t}-$ weight of treated wood sample, $\mathrm{kg}$;

$m$ - wood sample weight before treatment, $\mathrm{kg}$.

Wood surface modification with furfuryl alcohol. Conditioned wood samples were four times brushed with furfuryl alcohol with soaking reagent into wood between brushings. Then the treated wood samples were place in a desiccator above formic acid layer at $105 \pm 3{ }^{\circ} \mathrm{C}$ for 24 hours to polymerize furfuryl alcohol. The samples were dried in oven at $103 \pm 1{ }^{\circ} \mathrm{C}$ till constant mass. Mass gain was calculated according Eq. 6.

\section{Results and discussion}

As a natural renewable resource, wood is in general a non-toxic and easily accessible biomassderived material, but wood has drawbacks such as low dimensional stability by moisture sensitiveness, low resistance to bio-deterioration against fungi, and low resistance to UV irradiation [30]. Thermal modification (TM) is used to diminish these drawbacks [10;30;31]. TM of timber leads to a reduction in strength and the mode of failure, which generally becomes brittle in nature [30]. The TM wood initially brown colour is not stable and it fades and turn to grey in outdoors exposure [8-9]. The wood char is in general carbon - the chemical element with black or dark grey colour and it is most stable allotrope of carbon [32]. The surface charring will protect underlining wood from UV radiation that initiates weathering.

In the first stage of research the un-covered wood samples were charred at different temperatures (300, 400, 500 and 800) ${ }^{\circ} \mathrm{C}$ in the muffle oven to determine fast wood surface charring conditions. Wood samples ignited after 3-4 seconds since placement in the oven at highest temperature $800{ }^{\circ} \mathrm{C}$. Wood mass loss (ML) is used to characterise wood TM effect on the wood [10]. The trend of wood samples mass loss at $800{ }^{\circ} \mathrm{C}$ increased with increase of wood exposure to heat as it shown in Fig. 1. ML well correlates with thermal treatment intensity. The correlation ratio 0.969 was obtained between wood charring duration and mass loss (Eq. 1). It coincides with results of one-side charring of wood with hot plate [1; $33,34]$. Water uptake in charred and reference samples in the immersed conditions calculated according Eq. 3 is shown in the Fig. 2. Water uptake in the charred samples were only slightly decreased at room temperature, but it increased by additional two day soaking at $90{ }^{\circ} \mathrm{C}$ compared to absorption of reference samples. It is contrariwise to TM wood water absorption [10]. It could be caused by relatively high ratio of char to uncharred wood and athwart to edges grain effects. The wood charring at $800{ }^{\circ} \mathrm{C}$ could not be recommended due to fast ignition of wood.

A part of wood pyrolysis products are volatile, which in presence of oxygen ignite and burn in flame. Not volatilized part of pyrolysis products undergoes further condensation with forming intermediate products, which in additional pyrolysis reactions resulted in char formation. In ideal char will contain pure carbon, but pyrolysis intermediate products might contain chromophore groups which are responsible for a coloured char $[12 ; 15 ; 19 ; 24]$.

The measured with reflectance spectrophotometer colour coordinates values: lightness $L^{*}$ (varying from 0 for black to 100 for white), redness $a^{*}$ (varying from -100 for green to +100 for red on the green-red axis) and yellowness $b^{*}$ (varying from -100 for blue to +100 for yellow on the blue-yellow axis) characterized char colour. Total colour differences $\left(\Delta E^{*} a b\right)$ between charred and reference wood samples surfaces were calculated according Eq. 5. The colour change is observable $\Delta E^{*} a^{*} b^{*}$ value is greater than 6 SCI units [35]. Wood sample flaming created uneven colour of wood sample surface by reflexed of flame heat. 


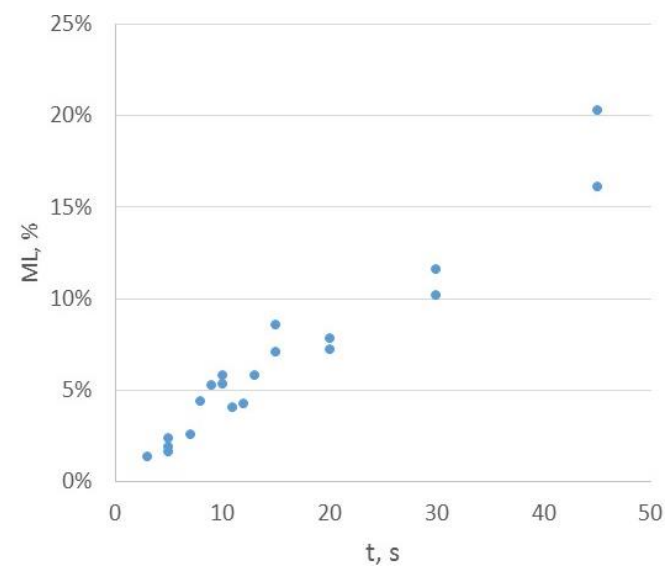

Fig. 1. Wood mass loss $(M L)$ dependence from exposure duration $(t)$ at $800{ }^{\circ} \mathrm{C}$

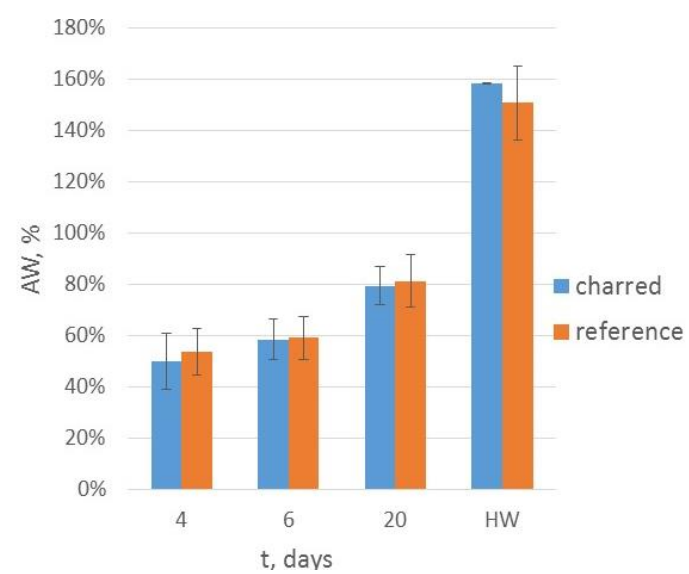

Fig. 2. Absorption of water at $20^{\circ} \mathrm{C}$ and in hot water $(\mathrm{HW})$ at $90^{\circ} \mathrm{C}$

Wood sample charring formed drastic $\Delta E^{*}$ change in average $51 \pm 1.1$ with decrease of $L^{*}$ component by $47 \pm 1.4$, low $a^{*}$ by $4.4 \pm 0.9$, and medium $b^{*}$ by $19.9 \pm 0.8 \mathrm{SCI}$ units in comparison with reference wood. The low $a^{*}$ and $b^{*}$ values of charred samples indicated high carbon content in the char as shown on Fig. 3.

The results of unexpected water up-take in charred wood and its surface colour unevenness of uncovered wood established the subsequent wood surface charring study to be carried out with wood samples covered with aluminium foil except one tangential surface. Aluminium foil prevent charring of athwart to grain edges that initiates ignition and prevents covered surfaces charring.

The wood one-side charring impeded the charred wood samples hydrophobic properties evaluation due to different properties of covered and un-covered surfaces. In addition to this, the heat transfer through window in aluminium foil covering created temperature gradient in the wood that resulted in the gradual wood TM. One-side water vapour diffusion through charred wood surface was used to evaluate charring effect on water vapour accumulation in the wood sample. As shown in Fig. 4 the charred wood had lesser water vapour accumulation than reference wood in average by $20 \pm 2.8 \%$ except first hour when uptake difference was lesser. That might point on the higher water absorption in the char layer than in the underlying TW wood layers. After char saturation the subsequent lowered water absorption was determined by TM wood layer underneath char.

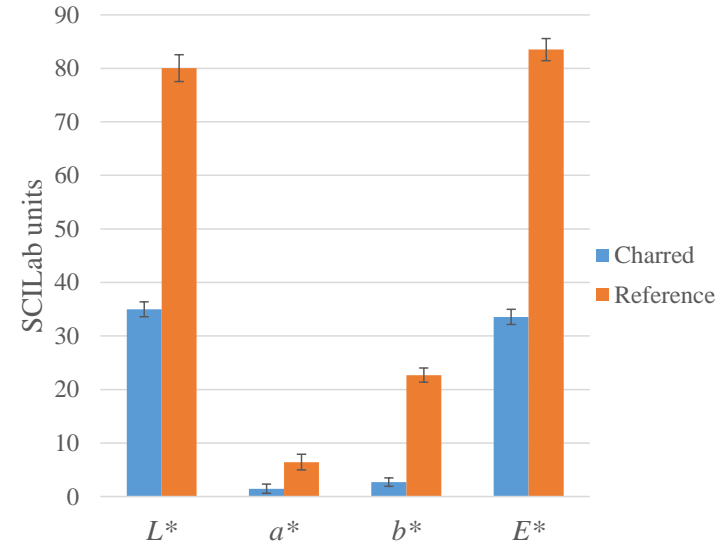

Fig. 3. Comparison of charred and reference wood surface colour coordinates $\left(L^{*}, a^{*}\right.$ and $\left.b^{*}\right)$ and total colour $\left(E^{*}\right)$



Fig. 4. One side water accumulation in charred and reference wood

Sustainable use of wood will include its recycling after constructions demolition. Such wood might be covered with different paints, remnants of plastering and a dirt in cracks as well as might have wood decaying fungi infection. Wood charring at high temperature could be one of demolition wood recycling 
methods. Wood surface brushing with sodium silicate (SS) a week before charring was used as model for demolition wood covered with inorganic base coating.

Water vapour accumulation in wood samples through charred and before modified with SS surface were lower in comparison with reference except the first half hour. The comparative hydrophobicity was calculated with Eq. 4 to highlight the modified and charred surface effect. As shown on the Fig. 5 during the first half the water vapour accumulation in charred wood was higher than in reference. It could be explained with effects silicon and sodium hydroxide formed from sodium silicate during charring. Water reaction with these substances increased water absorption in comparison with reference that gave negative $\mathrm{CH}$ value. After inorganic compounds saturation with water the water absorption decreased due to lower polarity of underlying heat treated wood layer. This should be taken into account in case of use of charred recycled wood, which had been polluted with inorganic substances.

The modified with SS and charred wood surface had comparatively very low colourfulness. Practically redness $a^{*}$ and yellowness $b^{*}$ colour-coordinates values were near zero and lightness were reduced in comparison with reference wood as shown in the Fig. 6 . The $L^{*}$ value was decreased of modified and charred wood surface in comparison with charred reference wood shown in the Fig.3 due to loose char layer of SS modified wood.

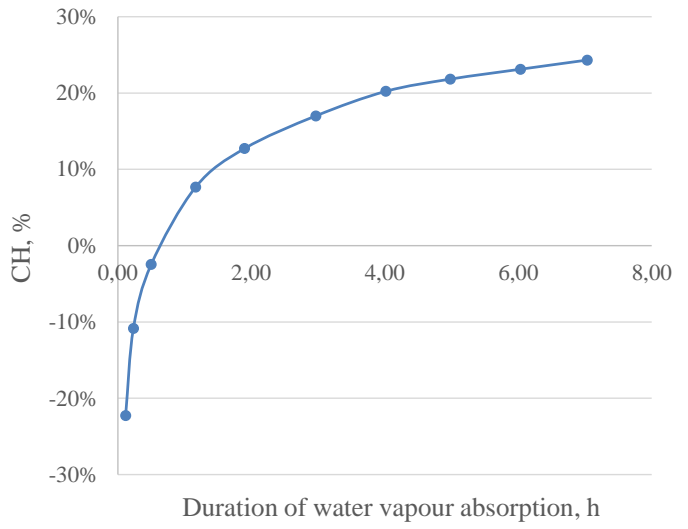

Fig. 5. Comparative hidrophobity $(\mathrm{CH})$ of charred and modified with SS wood surface

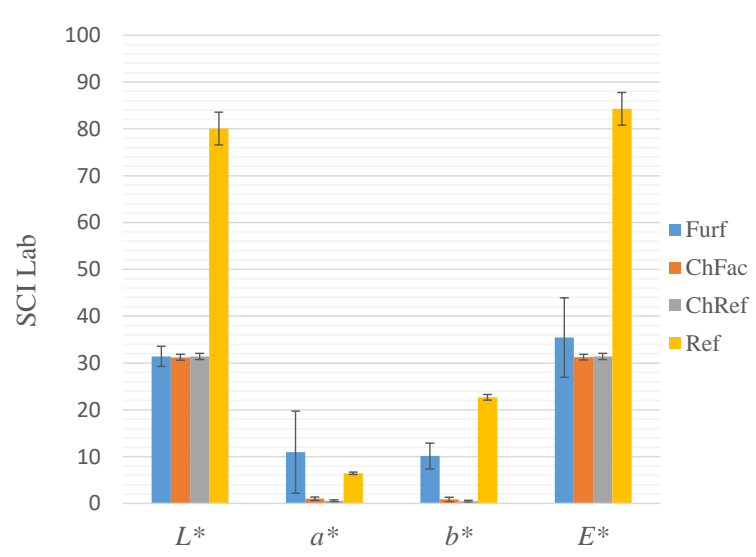

Fig. 7. Comparison of furfurylated (Furf), modified with formic acid and charred (ChFac), charred reference (ChRef) and reference (Ref) wood surface colour coordinates $\left(L^{*}, a^{*}\right.$ and $\left.b^{*}\right)$ and total colour $\left(E^{*}\right)$

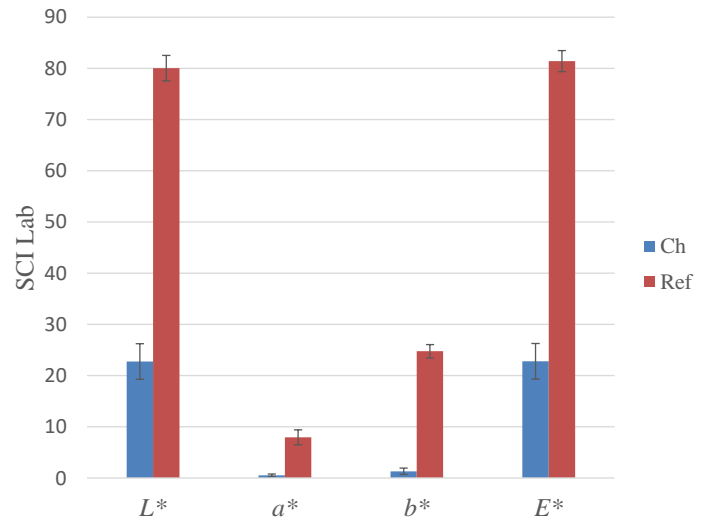

Fig. 6. Modified with sodium silicate and charred wood $(\mathrm{Ch})$ and reference (Ref) surface colour coordinates $\left(L^{*}, a^{*}\right.$ and $\left.b^{*}\right)$ and total colour $\left(E^{*}\right)$

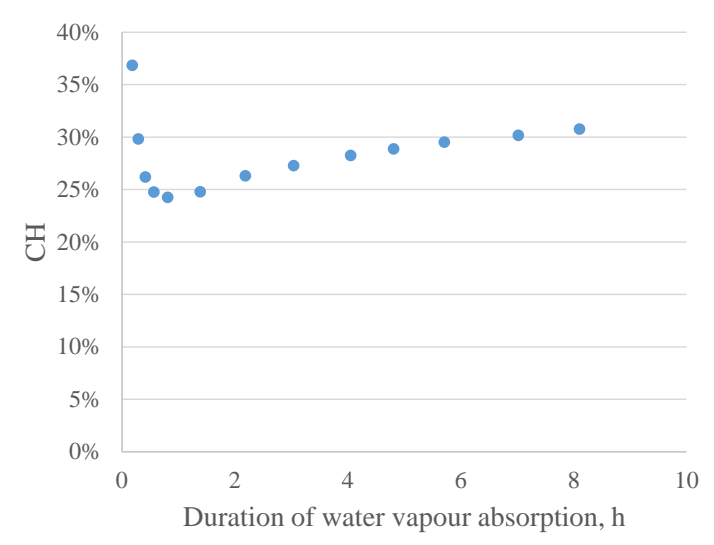

Fig. 8. Comparative hidrophobity $(\mathrm{CH})$ of modified with formic acid and then charred wood surface 
Hemicellulose is the first wood polymer component that decomposes when heated at temperature higher than $200{ }^{\circ} \mathrm{C}$ [15]. Hemicelluloses acetyl groups eliminates under pyrolysis conditions as acetic acid. It along with formic acid formed by pyrolysis product oxidation with oxygen might catalyse furan compounds brown polymer formation. These polymers might tint charred wood surface and alter char polarity. Four series of wood samples were used to evaluate char properties change by influence of formic acid. The first series wood sample surface were brushed with furan alcohol and then it was polymerized in formic acid vapours at elevated temperature to obtain furfurylated wood surface. The second series samples surface were brushed with formic acid and then charred. These woods surface colours were compared with charred reference wood (Fig, 3) and reference wood (Fig. 7). The $L^{*}$ and $E^{*}$ values of all kinds of charred sample series did not differ, but they differed from $L^{*}$ and $E^{*}$ values of un-charred reference wood. The redness of furfurylated wood were considerably higher than both kinds of charred wood. It points to possible furfuryl polymers burning during charring. Comparative hydrophobicity of treated with formic acid and then charred wood (Fig. 8) was higher than of modified with SS (Fig. 5) and charred wood samples.

\section{Conclusions}

The four modes of pine wood surface charring were investigated. Two modes of all surface charring or one side surface charring for new claddings, the treatment with sodium silicate as model for demolition wood charring and pre-treatment with formic acid for charred surface water vapour absorption decrease. The main results of research are:

1. Wood char layer does not act as wood protector or have little effect on underlying wood moisture diminishing.

2. Based on results of one-side water vapour up-take through wood surface impregnated with sodium silicate and subsequently charred was found that inorganic compounds increased surface hydrophilic nature.

3. Wood surface pre-treatment with formic acid before charring increased one side charred wood hidrophobity.

4. Wood char colour redness a* and yellowness $b^{*}$ low values confirm high wood's charring degree.

5. The method of water vapour up-take through charred wood surface assessment were developed.

\section{Acknowledgements}

In accordance with the contract No.1.2.1.1/18/A/004 between "Forest Sector Competence Centre" Ltd. and the Central Finance and Contracting Agency, concluded on 17th of April, the study is conducted by the "Pavasars Wood Constructions" Ltd. With support from the European Regional Development Fund (ERDF) within framework of the project "Forest Sector Competence Centre".

\section{References}

[1] Kymäläinen M., Turunen H., Čermák P., Hautamäki S., and Rautkari L. Sorption-related characteristics of surface charred spruce wood. Materials, vol. 11, 2018, pp. 2083-2098.

[2] Mayes D. Trends impacting modified wood products and the need for continued evolution of thermally modified wood. Proceedings of the Eighth European Conference on Wood Modification, October 26-27, 2015, Paasitorni, Helsinki, Finland p. 6.

[3] Zelinka S.L. Ringman R., Pilgård A., Thybring E.E., Jakes J.E., and Richter K. The role of chemical transport in the decay resistance of modified wood. Proceedings of the Eighth European Conference on Wood Modification, October 26-27, 2015, Paasitorni, Helsinki, Finland pp. 35-43.

[4] Thybring E.E., Kymäläinen M., Rautkari L. Moisture in modified wood and its relevance for fungal decay. iForest, vol. 11, 2018, pp. 418-422.

[5] Sandberg D., Kutnar A. Thermally modified timber: recent developments in Europe and North America. Wood and Fiber Science, vol. 48, 2016, pp. 28-39.

[6] Boonstra M.J., van Acker J., Tjeerdsma B.F., Kegel, E.V. Strength properties of thermally modified softwoods and its relation to polymeric structural constituents. Annals of Forest Science, vol. 64, 2007, pp. 679-690. 
[7] Shi J.L., Kocaefe, D., Zhang, J. Mechanical behaviour of Quebec wood species heat-treated using ThermoWood process. Holz als Roh- und Werkstoff, vol. 65, 2007, pp. 255-259.

[8] Jämsä, S., Ahola, P., Viitaniemi, P. Long-term natural weathering of coated ThermoWood. Pigment and Resin Technology, 2000, 29, 68-74.

[9] Virta, J. Cupping of wooden cladding boards in cyclic conditions-A study of heat-treated and nonheat-treated boards. Building and Environment, 2005, 40, 1395-1399.

[10] Hill, C.A.S. Wood Modification: Chemical, Thermal, and Other Processes; Chichester, UK, John Wiley \& Sons Ltd.: 2006, 239 p.

[11] Čermák P., Rautkari L., Horáček P., Saake B., Rademacher P, and Sablik P. Analysis of dimensional stability of thermally modified wood affected by re-wetting cycles. Bioresources, vol. 10, 2015, pp. 3242-3253.

[12] Friquin K.L. Material properties and external factors influencing the charring rate of solid wood and glue-laminated timber. Fire and Materials, vol. 35, 2011, pp. 303-327.

[13] Shen D., Fang M., Luo Z., Cen K. Modelling pyrolysis of wet wood under external heat flux. Fire Safety Journal, vol. 42, 2007, pp. 210-217.

[14]Hugi E., Wuersch M., Risi W., Wakili K.G. Correlation between charring rate and oxygen permeability for 12 different wood species. Journal of Wood Science, vol. 53 (1), 2007 71-75.

[15] Yang H., Yan R., Chen H., Lee D.H., Zheng C. Characteristics of hemicellulose, cellulose and lignin pyrolysis. Fuel, vol. 86, 2007, pp. 1781-1788.

[16] Bartlett A.I., Hadden R.M., and Bisby L.A. A review of factors affecting the burning behaviour of wood for application to tall timber construction. Fire Technology, vol. 55, 2019, pp. 1-49.

[17] Di Blasi C., Hernandez E.G., Santoro A. Radiative pyrolysis of single moist wood particles. Industrial \& Engineering Chemistry Research, vol. 39, 2000, pp. 873-882.

[18] Shen D., Gu S. The mechanism for thermal decomposition of cellulose and its main products. Bioresource Technology, vol. 100, 2009, pp. 6496-6504.

[19] Kawamoto H., Morisaki H., Saka S. Secondary decomposition of levoglucosan in pyrolytic production from cellulosic biomass. The Journal of Analytical and Applied Pyrolysis, vol. 85, 2009, pp. 247-251.

[20] Grønli M.G., Melaaen M.C. Mathematical model for wood pyrolysis comparison of experimental measurements with model predictions. Energy \& Fuels, vol. 14, 2000, pp. 791-800.

[21] Schmid J., Just A., Klippel M., Fragiacomo M. The reduced cross-section method for evaluation of the fire resistance of timber members: discussion and determination of the zero-strength layer. Fire Technology, vol. 51, 2014, pp. 1285-1309.

[22] Babrauskas V. Charring rate of wood as a tool for fire investigations. Fire Safety Journal, vol. 40, 2005, pp. 528-554.

[23] Cachim P.B., Franssen J.-M. Assessment of Eurocode 5 charring rate calculation methods. Fire Technology, vol. 46, 2010, pp. 169-181.

[24] Di Blasi C., Branca C., Santoro A., Gonzalez Hernandez E. Pyrolytic behaviour and products of some wood varieties. Combustion and Flame, vol. 124, 2001, pp. 165-177.

[25] Yang T.-H., Wang S.-Y., Tsai M.-J., Lin C.-Y. The charring depth and charring rate of glued laminated timber after a standard fire exposure test. Building and Environment, vol. 44, 2009, pp, 231-236.

[26] Reszka P., Torero J. In-depth temperature measurements in wood exposed to intense radiant energy. Experimental Thermal and Fluid Science, vol. 32, 2008, pp. 1405-1411.

[27] Lizhong Y., Zaifu G., Yupeng Z., Weicheng F. The influence of different external heating ways on pyrolysis and spontaneous ignition of some woods. Journal of Analytical and Applied Pyrolysis, vol. 78, 2007, pp. 40-45.

[28] Lunguleasa A., Spirchez C. Torrefication of lamellar panels made of oak and spruce wood species. Wood Research, vol. 62, 2017, pp 319-328.

[29] Konopka A., Baranski J., Orlowski K.A., Chuchala D. The effect of drying intensity on the color changes of pine wood (Pinus sylvestris L.) Chip and Chipless Woodworking Processes, vol. 12, 2020, pp. 79-84.

[30] Sandberg D., Kutnar A., Mantanis G. Wood modification technologies - a review. iForest, vol. 10, 2017, pp. 895-908. 
[31] Esteves B.M., Pereira H.M. Wood modification by heat treatment: a review. BioResources, vol. 4, 2009, pp. 370-404.

[32] Brown C., Ford M. Higher level chemistry. Second edition. Harlow, Perarson Education Ltd. 2014, $980 \mathrm{p}$.

[33] Kymäläinen M., Hautamäki S., Lillqvist K., Segerholm K., and Rautkari L. Surface modification of solid wood by charring. Journal of Materials Science, vol. 52, 2017, pp. 6111-6119.

[34] Čermák P., Dejmal A., Paschová Z., Kymäläinen M., Dömény J., Brabec M., Hess D., and Rautkari L. One-sided surface charring of beech wood. Journal of Materials Science, vol. 54, 2019, pp. 9497 9506.

[35] Barcík Š., Gašparík M., and Razumov E. Effect of temperature on the color changes of wood during thermal modification. Cellulose Chemistry and Technology, vol. 49, 2015, pp. 789-798. 